\title{
Temporal changes in the polychaete infaunal community surrounding a Hawaiian mariculture operation
}

\author{
Han W. Lee ${ }^{1}$, Julie H. Bailey-Brock ${ }^{1,2, *}$, Michelle M. McGurr ${ }^{2}$ \\ ${ }^{1}$ Department of Zoology, University of Hawai'i, 2538 McCarthy Mall, Honolulu, Hawai'i 96822, USA \\ ${ }^{2}$ Water Resources Research Center, University of Hawai'i, 2540 Dole St., Honolulu, Hawai'i 96822, USA
}

\begin{abstract}
Benthic monitoring efforts in the vicinity of a Pacific threadfin Polydactylis sexfilis mariculture venture have allowed us to examine eutrophic effects on the infaunal community. Polychaete infaunal communities from 2 sites near the point source were compared to 2 control stations beyond the range of fish feed and wastes. Regression analysis indicated significant decreases in ShannonWeiner diversity over time and near the effluent source. Non-metric multidimensional scaling (nMDS) showed a progression of species succession and turnover at impacted sites but relatively unchanging polychaete communities at control sites. An analysis of similarity (ANOSIM) indicated significant differences between community structures at impacted and control sites but less obvious differences over time. An abundant and regionally widespread polychaete Pionosyllis heterocirrata had disappeared from impacted sites. Increasing abundances of 2 opportunistic polychaetes, Capitella capitata (complex) and Ophryotrocha adherens, resulted in decreasing Shannon-Weiner diversity values $\left(H^{\prime}\right)$ at impacted stations. Expanding populations of $C$. capitata and $O$. adherens seem to be preceded by high densities of Myriochele oculata. These 3 species may represent an order of succession due to attrition by anoxia in Hawaiian waters. Deviation of the infaunal polychaete community at impacted sites resulting from the appearance of polychaete pollution indicators, low species richness resulting from the disappearance of ambient polychaete species and depressed community abundance reflect the effects of fish mariculture on the benthic community. Such effects may be diluted by the open-ocean location on the south shore of $\mathrm{O}^{\prime} \mathrm{ahu}$, Hawai'i.
\end{abstract}

KEY WORDS: Aquaculture · Environmental monitoring $\cdot$ Eutrophication $\cdot$ Hawai'i $\cdot$ Indicator species · Polychaetes

\section{INTRODUCTION}

The environmental effects of open-water mariculture have been reported from studies conducted internationally, including the UK (Henderson \& Ross 1995), Eastern Canada (Pocklington et al. 1994, Pohle et al. 2001), Australia (Ritz et al. 1989, Crawford 2003) and Japan (Tsutsumi 1995, Yokoyama 2002). Mariculture operations produce fecal matter and excess food that leads to organic enrichment of the surrounding benthos, creating reducing conditions in the sediment and oxygen depletion of the bottom water (Hargrave 1994,
Tsutsumi 1995, Pohle et al. 2001). Microbial degradation of surplus organics often leads to benthic conditions characterized by anoxic conditions, low redox potential and elevation of the redox potential discontinuity (RPD) layer (Henderson \& Ross 1995). Previous aquaculture operations have been operated in embayments (e.g. Tsutsumi 1987, 1995, Pohle et al. 2001, Yokoyama 2002), which usually contain low energy environments with reduced dilution effects from currents. Open-ocean mariculture operations are relatively new and provide a location in which enrichment effects can be buffered by increased current activity 
and dilution as well as a deeper operation site (Fernandes et al. 2001, Henderson et al. 2001).

Commercial culturing of the Pacific threadfin Polydactylus sexfilis was recently introduced to openocean waters of Hawai'i. Known locally as moi, this popular finfish was once reserved for Hawaiian royalty (Titcomb 1972) and is a popular item on restaurant menus (Chambers et al. 2001). Experimental phases of a mariculture operation culturing the Hawaiian moi began in April 1999 with 1 cage $2 \mathrm{~km}$ offshore from Ewa Beach in Mámala Bay, O'ahu, Hawai'i (Bybee \& Bailey-Brock 2003). The commercial phases of mariculture began with 1 cage in November 2001 and increased to 3 cages in subsequent years. The amount of nutrient input into the system has increased with additional open-water enclosures installed over the past 5 yr (Fig. 1).

Like most aquaculture ventures, the effects of nutrient enrichment from the fish cages on the macrobenthic environment are evident in monitoring studies. Regulatory and pollution control authorities have used benthic community structure in the past to gauge organic enrichment (Pearson \& Rosenberg 1978, Henderson \& Ross 1995). Analysis of faunal community changes has reportedly been more sensitive than geochemical parameters in detecting organic enrichment (Carroll et al. 2003). Infaunal community analyses supplemented by measurement of geochemical properties are used to assess enrichment intensity and benthic health for this mariculture operation. Benthic sampling data collected from the area surrounding the mariculture cage over a 36 mo period has been examined within the context of several long-term studies con-

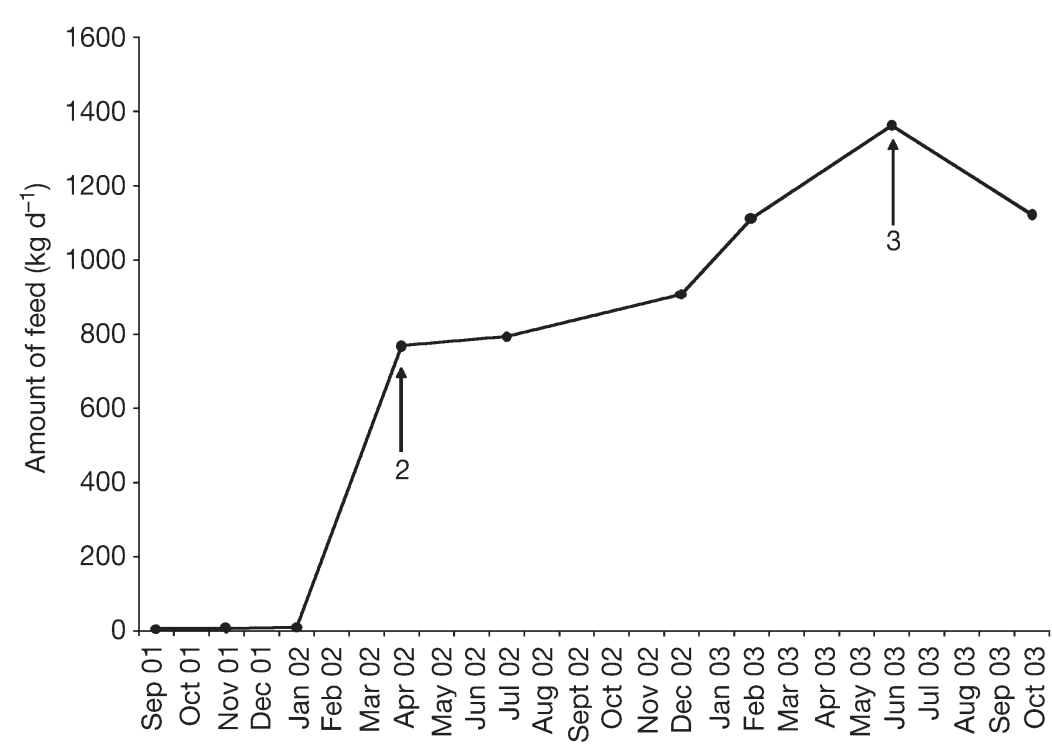

Fig. 1. Feed data as reported by Cates International. New cages were added in March 2002 and June 2003 ducted at similar depths in the surrounding area of Mámala Bay, O'ahu (Swartz et al. 2001, Bailey-Brock et al. 2002).

From infaunal community data, univariate measures such as species diversity and evenness are calculated and correlated with changes in organic levels (Gray et al. 1990). Declining species richness especially coupled with increasing infaunal abundance, as well as decreasing diversity and evenness values, are associated with pollution (Krassulya 2001). Comparisons of species composition between native, unaffected communities and communities from impacted or polluted environments may be performed using multivariate analyses such as a non-metric multidimensional scaling (nMDS, Clarke \& Warwick 2001). All these techniques are useful and often combined for monitoring sewage outfall effluent and effects of organic enrichment on infaunal community succession (Pearson \& Rosenberg 1978).

Designating species that thrive in disturbed environments as indicators of organic enrichment is another measure that has gained acceptance. While the concept of indicator species is widely applicable, ubiquitous usage of indicator taxa has been questioned (Bustos-Baez \& Frid 2003). Polychaetes such as Capitella capitata and Ophryotrocha spp. have shown potential as enrichment indicators in temperate environments and in Hawai'i (Grassle \& Grassle 1974, Tsutsumi 1987, 1990, 1995, Henderson \& Ross 1995, Bailey-Brock 1996, Paavo et al. 2000, Bailey-Brock et al. 2002, Bybee \& Bailey-Brock 2003, Simonini 2002, Brooks et al. 2003). High abundances of invertebrate indicator species coupled with low numbers of ambient or native species in the community is a signal of disturbance. Low numbers of indicators may reflect their natural population density in the unperturbed community. Anoxic conditions also affect the distribution of indicator species such as C. capitata (Gamenick et al. 1998). This study illustrates a change in macrobenthic community composition from a native assemblage to one dominated by indicator species in response to mariculture activity.

\section{MATERIALS AND METHODS}

Study sites. The mariculture cages were moored at a designated site about $2 \mathrm{~km}$ offshore and $13 \mathrm{~km}$ west of Honolulu Harbor. Four sampling sites were at the cage and at varying distances from it (Fig. 2). The Sea Station cage system developed by Ocean Spar Technologies is a biconical structure enclosing ca. $3000 \mathrm{~m}^{3}$ and sus- 


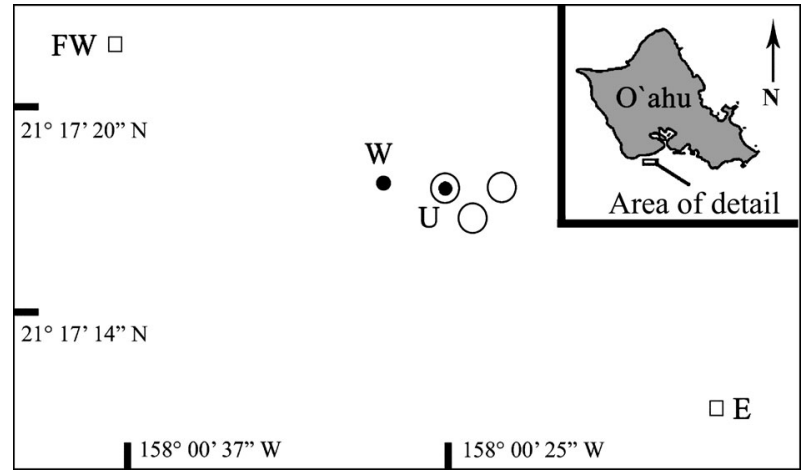

Fig. 2. Map of study area including latitudinal and longitudinal coordinates. Site $U$ is located under western lip of enclosure, Site W is $80 \mathrm{~m}$ from center of enclosure, Site FW is $390 \mathrm{~m}$ distant, and Site E is $360 \mathrm{~m}$ away. Control sites: ( $\square$ ), impacted sites: $(\bullet)$, mariculture enclosures on map: $(\bigcirc)$

pended ca. $10 \mathrm{~m}$ above a sand bottom. New fry were added to an inner netted area, while fish ready for harvest occupied the outer sector. Up to 130000 moi of 2 age classes could be enclosed within each cage. Solid sections of the lower conic mesh helped direct falling food pellets toward a catch basin where they decomposed, and residue was dispersed by currents.

SCUBA divers collected samples from sediments between 31 and $35 \mathrm{~m}$ depths over 12 sampling periods between November 2001 and November 2004. Two stations under (U) and $80 \mathrm{~m}$ west (W) of the fish cages were designated as impacted, while 2 stations $390 \mathrm{~m}$ westward (FW) and $360 \mathrm{~m}$ eastward (E) of the cages were control sites. Sites were selected on the premise that currents move predominantly westward. Hydrodynamic properties were characterized by project divers and oceanographic models created for the nearby Barbers Point and Sand Island sewage outfalls. Bottom currents measured at the Barber's Point outfall (less than $1 \mathrm{~km}$ from Site E) never exceeded $50 \mathrm{~cm} \mathrm{~s}^{-1}$ (Roberts 1995).

Sampling methods: environmental variables. SCUBA divers collected 3 replicate $125 \mathrm{ml}$ sediment cores in clear plastic Nalgene bottles from each of the 4 stations for qualitative measurements of electrochemical oxidation reduction potential (ORP) and granulometric analyses. The ORP of each core's surface was measured using a handheld Oakton ORP meter with direct electrode contact to sediment cores. Presence of sulfide in sediment cores was determined by olfactory detection. Total organic carbon analyses of carbonate sand samples were measured using the $\mathrm{HCl}$ vapor digestion method (Hedges \& Stern 1984). However, results did not meet $\mathrm{QA} / \mathrm{QC}$ requirements, were not interpretable, and are not presented here.
Sediment grain sizes and distributions were assessed using a wet sieve gravimetric procedure (McCarthy 1996). A fraction was removed to a nested sieve series suspended over a clean white bucket. The collected slurry was drawn off and filtered to remove the finest silt fraction. All grain size fractions were dried for a minimum of $12 \mathrm{~h}$ at $80^{\circ} \mathrm{C}$ before weighing. This process lost any information on sedimentary stratification. McCarthy's (1996) detailed sedimentary study did not find any evidence of grain size stratification in sediments from east Mámala Bay. The major grain size fractions agreed within $11 \%$ of their respective values, supporting an assumption of uniform processing.

Sampling methods: benthic invertebrates. SCUBA divers collected $100 \mathrm{~cm}^{2}$ sediment cores $5 \mathrm{~cm}$ deep from 4 stations over 12 sampling dates. Three replicates per sampling were taken from within a $2 \mathrm{~m}^{2}$ area previously undisturbed by diving activities at each site. Cores for infaunal analyses were preserved in $10 \%$ buffered formalin and elutriated over $0.5 \mathrm{~mm}$ sieve according to procedures detailed by Sanders (1958). Infauna were sorted, identified to lowest possible taxa according to Bailey-Brock (1987) and enumerated.

Data analysis. Shannon-Wiener diversity $\left(\log \mathrm{e}_{;} \mathrm{H}^{\prime}\right)$ and Pielou's evenness $(J)$ were calculated for each sediment core for all sampling dates. Spatial and temporal variation in $H^{\prime}$ was analyzed by polynomial regression, using distance $(\mathrm{m})$ from the effluent source and time (d) since the first sampling as independent variables.

Changes in community composition were analyzed using a matrix of multivariate ecological similarity coefficients. Bray-Curtis similarity coefficients between samples were calculated based on the similarity of infaunal community structure. Each species' contribution to the Bray-Curtis coefficient was determined by those species' abundances in the compared samples. Samples with many species in common at similar abundances had high Bray-Curtis similarity coefficients. Construction of the Bray-Curtis similarity matrix utilized polychaete abundance data that were pooled for the 3 sediment cores from each site during each sampling period and then 4 th root transformed.

The Bray-Curtis similarity matrix was used in the construction of a 2-dimensional non-metric multidimensional scaling (nMDS). This ordination plot is a visualization of a 2-factor analysis of similarities (ANOSIM, Clarke \& Warwick 2001) crossed between sites and sampling dates. This procedure allowed us to test for significant differences in polychaete community structure between sampling periods using average site values and between sites using average sampling date values. Each ANOSIM procedure entailed the use of 999 permutations. 


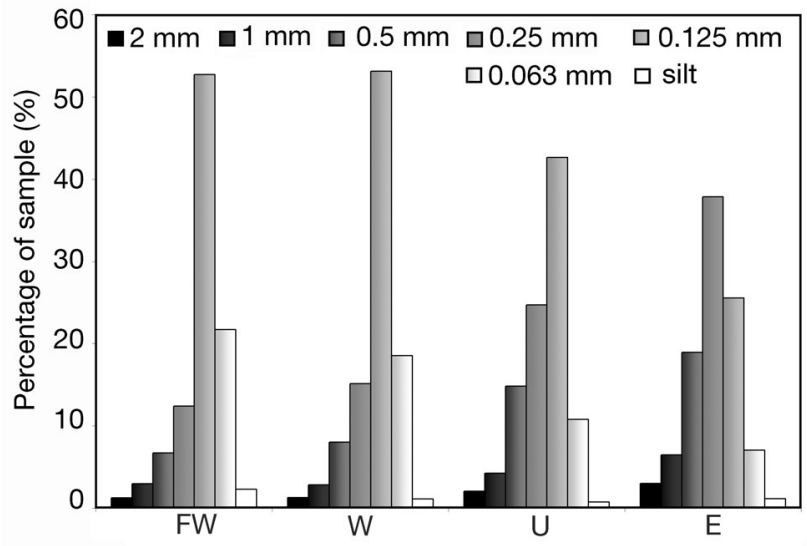

Fig. 3. Average percentages of each grain size from 8 samplings. Fractions of smaller grain sizes increase toward west while fractions of larger grain sizes increase toward east

PRIMER's similarity percentage (SIMPER, Clarke \& Warwick 2001) analysis identifies discriminating and typifying species in a comparison of infaunal communities (Clarke \& Warwick 2001). This analysis ranked each species' contribution to community structure based on abundances found in replicates for each site. Common species with similar abundances between replicates contributed most to Bray-Curtis similarity within a sample. Low standard deviations of these coefficients suggested consistency in the species' abundances across replicates. Characteristic species were identified by a high ratio of Bray-Curtis similarity contribution to a coefficient's standard deviation. Discriminating species were identified using the Bray-Curtis dissimilarity coefficient, which was calculated using differences in species abundances between samples (Clarke \& Warwick 2001).

Analyses were performed with MINITAB 13.32 for Windows (Minitab 2000) and PRIMER 5 for Windows v. 5.2 .9 (PRIMER-E 2002).

\section{RESULTS}

\section{Granulometry}

A general trend indicated that grains found in western sampling sites were finer than grains found in eastern sites (Fig. 3). Since smaller grain sizes would be carried down current more easily than larger sand grains, average grain sizes decreased from Site E to FW. The greatest separation of grain sizes was between 0.125 and $0.25 \mathrm{~mm}$. Although sediment compositions showed slight variations between sites, granulometric profiles were still highly similar (Fig. 2).
Oxidation-reduction potential. ORP measurements at impacted sites were consistently lower than measurements at control sites (Fig. 4). The difference between ORP measurements from control and impacted sites increased since the initial sampling. Site U samples had redox potentials consistently below the range of the meter used, which coincided with sulfuric odors detected by collectors. Such effects are not observed at other sites.

Infaunal data. Shannon-Weiner diversity values at Site U decreased from (2.85 average) the November 2001 sampling to the lowest levels found during this study (1.02 average) in December 2002. Diversity values at Site W fluctuated between 0.96 (November 2004) and 2.61 (April 2002). In contrast, diversity values at Site FW never decreased below 1.78 and had a peak level of 2.67 in January 2002. Site E had even higher diversity, ranging from 2.19 to 2.81 (Fig. 5). Decreases in Pielou's evenness (Fig. 6) and ShannonWeiner diversity values (Fig. 5) at Sites U and W were primarily attributed to increased dominance of opportunistic polychaetes Capitella capitata (complex) and Ophryotrocha adherens (Fig. 5) and a concomitant decrease in species richness (Fig. 7). Percent abundance of these 2 opportunists at impacted sites ranged from 8.4 to $84.9 \%$ of all polychaetes. Fluctuations in their respective percent abundances were roughly inversely related to fluctuations in Shannon-Weiner diversity values. Only 10 species of polychaetes were found at Site U in December 2002, resulting in the lowest average Shannon-Weiner values found during the study period. Except for a few data points, Pielou's evenness values at impacted sites were depressed relative to control sites.

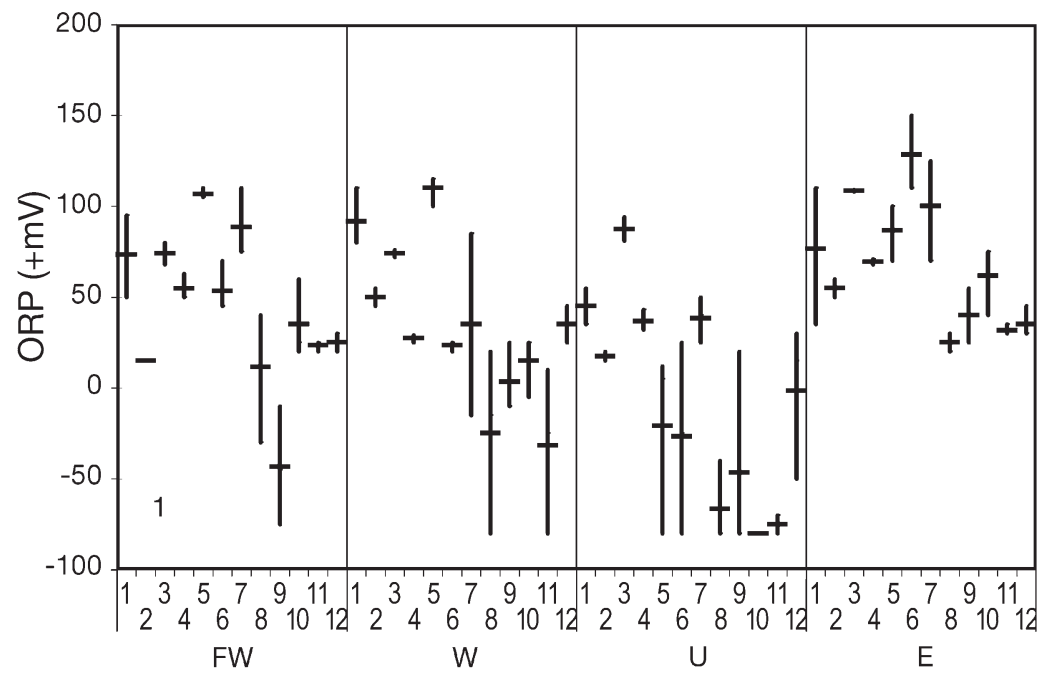

Fig. 4. Range of ORP measurements and their averages as shown by a - . Numbers on $x$-axis correspond to sampling period for each station. 1: Nov. 2001; 2: Jan. 2002; 3: Apr. 2002; 4: Jul. 2002; 5: Dec. 2002; 6: Feb. 2003; 7: Jun. 2003; 8: Oct. 2003; 9: Feb. 2004; 10: May 2004; 11: Sep. 2004; 12: Nov. 2004 


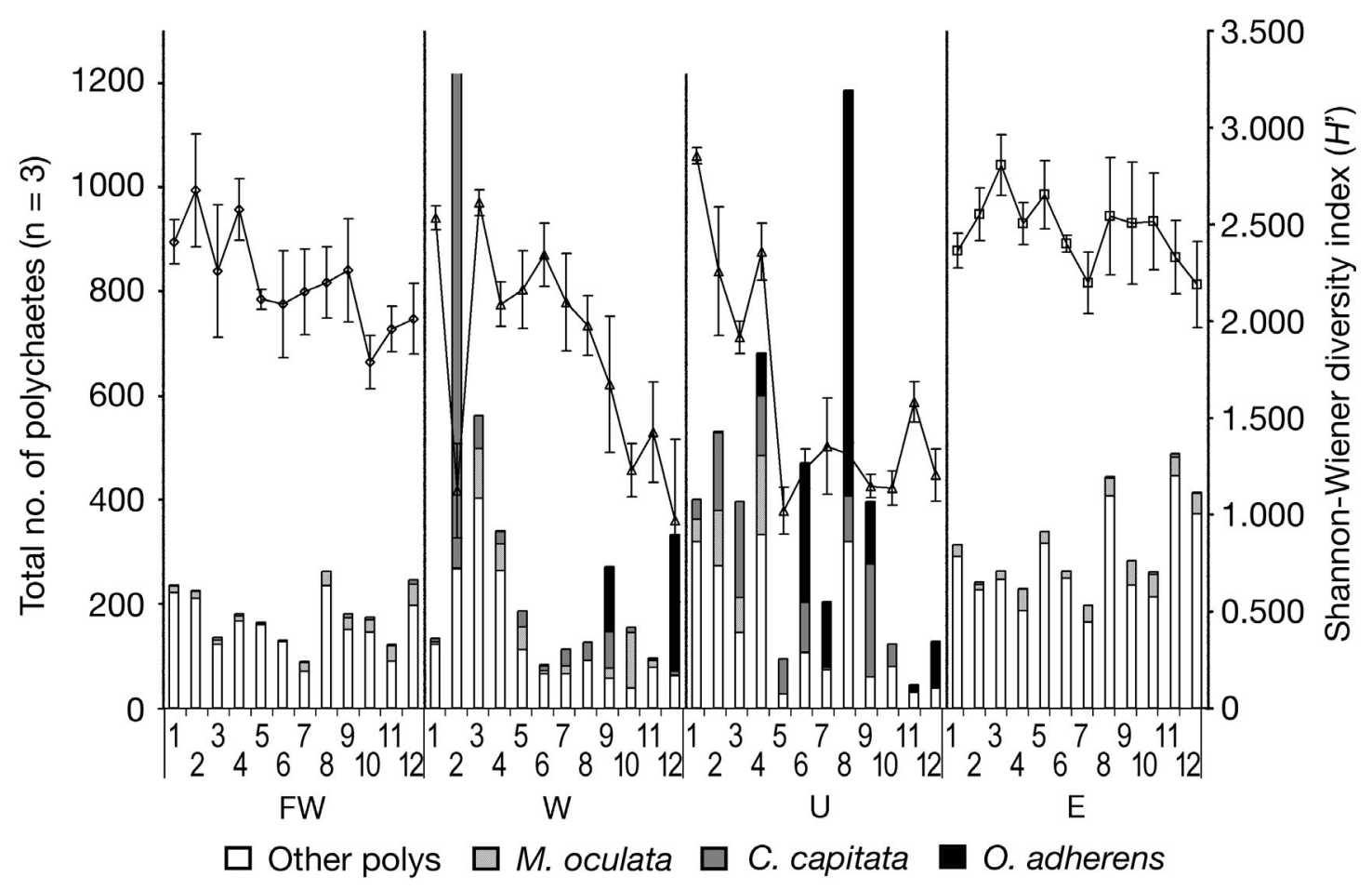

Fig. 5. Abundances of indicator species as fraction of total polychaete abundance for each station. Numbers on $x$-axis correspond to sampling period for each station. Ophryotrocha adherens and Capitella capitata are found in impacted stations and rarely found in reference stations. A line graph of Shannon-Weiner diversity values for each site is plotted on secondary $y$-axis. 1: Nov. 2001; 2: Jan. 2002; 3: Apr. 2002; 4: Jul. 2002; 5: Dec. 2002; 6: Feb. 2003; 7: Jun. 2003; 8: Oct. 2003; 9: Feb. 2004; 10: May 2004; 11: Sep. 2004; 12: Nov. 2004

Shannon-Weiner diversity varied significantly both over time and with distance from the cages (Table 1). Because one control station was up-current from the cages (negative distance) and the other was down-current (positive distance), the positive coefficient for distance squared indicated increasing diversity with greater distance from the effluent source in either direction. The negative coefficient for time reflected a decrease over the course of the study in diversity, averaging across the sites. The positive coefficient for the interaction of time and distance ${ }^{2}$ indicated that the difference between the impacted stations under or near the cages and the control stations further away increased over time. Higher-order terms were included to decrease lack of fit, but we were not able to construct a model without significant lack of fit. The principal lack of fit was the 3 replicates from Site W in January 2002, which had unusually high density of Capitella capitata and low diversity despite species richness comparable to the previous sampling of the same site.
The relatively close grouping in the nMDS of E and FW across all sampling dates showed consistent infaunal communities found through time (Fig. 8). These communities represented ambient communities that would be found in the absence of artificial influxes of

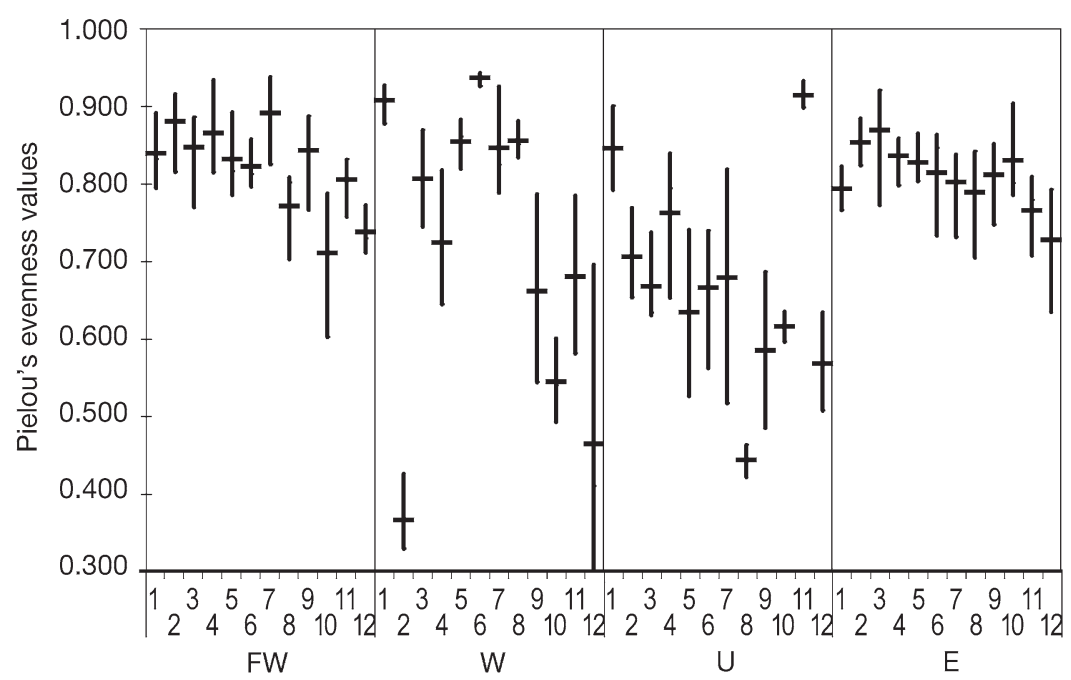

Fig. 6. Pielou's evenness levels for each site over the course of our samplings. Site U consistently has lowest levels of community evenness. 1: Nov. 2001; 2: Jan. 2002; 3: Apr. 2002; 4: Jul. 2002; 5: Dec. 2002; 6: Feb. 2003; 7: Jun. 2003; 8: Oct. 2003; 9: Feb. 2004; 10: May 2004; 11: Sep. 2004; 12: Nov. 2004 


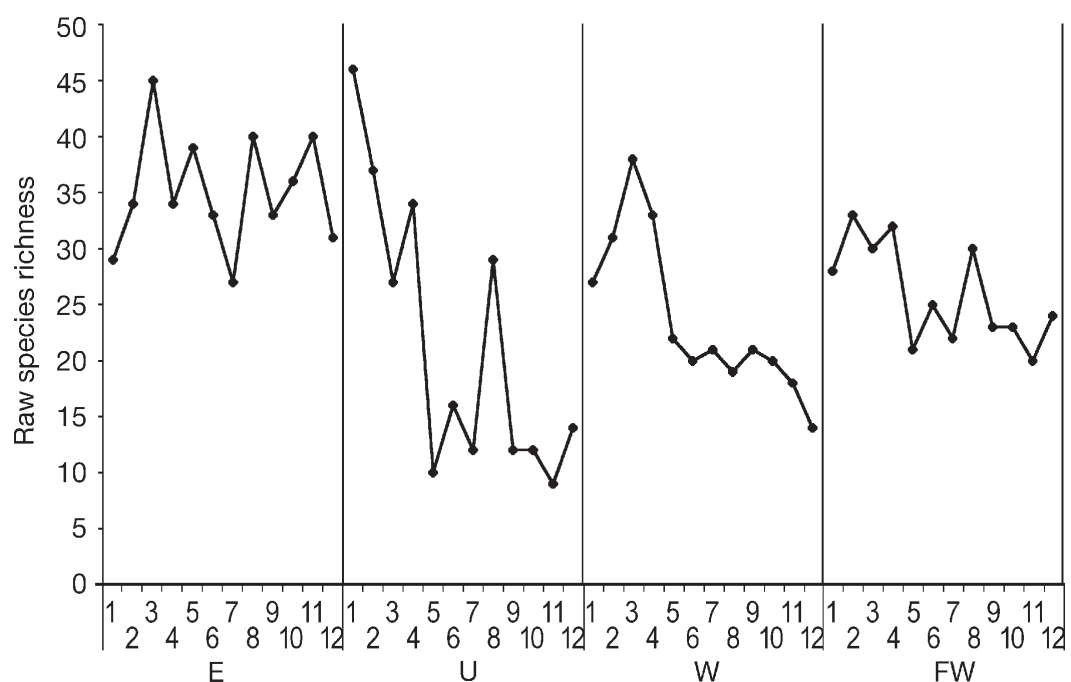

Fig. 7. Total numbers of polychaete species found based on pooled data for each sampling date. 1: Nov. 2001; 2: Jan. 2002; 3: Apr. 2002; 4: Jul. 2002; 5: Dec. 2002; 6: Feb. 2003; 7: Jun. 2003; 8: Oct. 2003; 9: Feb. 2004; 10: May 2004; 11: Sep. 2004; 12: Nov. 2004

organic matter. Initial samplings of impacted sites yielded infaunal communities relatively similar to those found at control sites. In successive samplings, a gradual infaunal species turnover at Site U resulted in a deviation from the ambient infaunal community. Until the June 2003 sampling, infaunal communities sampled at Site W were more similar to Sites E and FW than to Site U. Over time, the community structure at Site $\mathrm{W}$ began to resemble Site U samples more than

Table 1. Results of regression analysis of Shannon-Weiner diversity values with centered predictor variables

\begin{tabular}{|c|c|c|c|c|}
\hline Predictor & Coeff & $\mathrm{df}$ & Seq SS & $\mathrm{p}$ \\
\hline Constant & 1.5248 & & 0.000 & \\
\hline Distance & 2.7519 & 1 & 1.2905 & 0.000 \\
\hline Days & -0.34335 & 1 & 9.1036 & 0.000 \\
\hline Days $\times$ Distance & -0.02626 & 1 & 0.2242 & 0.718 \\
\hline Distance $^{2}$ & 0.28664 & 1 & 12.8425 & 0.000 \\
\hline Days $^{2}$ & 0.17025 & 1 & 0.0733 & 0.000 \\
\hline Days $\times$ Distance $^{2}$ & 0.12736 & 1 & 1.9973 & 0.000 \\
\hline Distance $\times$ Days $^{2}$ & -1.9832 & 1 & 0.0097 & 0.000 \\
\hline Distance $^{3}$ & -1.4475 & 1 & 1.094 & 0.000 \\
\hline Days $^{3}$ & -0.0227 & 1 & 0.0308 & 0.576 \\
\hline Days $^{2} \times$ Distance $^{3}$ & 1.0239 & 1 & 4.4845 & 0.000 \\
\hline Distance $\times$ Days $^{3}$ & 0.00185 & 1 & 0.0002 & 0.964 \\
\hline \multicolumn{3}{|c|}{$\begin{array}{l}\mathrm{R}-\mathrm{Sq}=70.7 \% \mathrm{R}-\mathrm{Sq}(\text { pred })=65.74 \% \\
\text { ANOVA }\end{array}$} & \multicolumn{2}{|c|}{$\mathrm{R}-\mathrm{Sq}(\operatorname{adj})=68.3 \%$} \\
\hline Source & $\mathrm{df}$ & MS & $F$ & $\mathrm{p}$ \\
\hline Regression & \multicolumn{2}{|c|}{2.8319} & 28.98 & 0.000 \\
\hline Residual error & 132 & 0.0977 & \multirow{4}{*}{6.41} & \multirow{3}{*}{0.000} \\
\hline Lack of fit & 36 & 531 & & \\
\hline Pure error & \multicolumn{2}{|c|}{0395} & & \\
\hline Total & \multicolumn{2}{|c|}{143} & & \\
\hline
\end{tabular}

controls. Two-way crossed ANOSIM determined significant differences between sites averaged across all dates as well as significant differences between dates averaged across all sites. However, separate ANOSIMs using only the first and last 6 dates yielded no significant differences (Table 2).

The 3 species that best typified their respective sites (i.e. had the greatest ratio of contribution to Bray-Curtis similarity: standard deviation) were designated with A, B and C (Table 3). Species that best typified control sites were Pionosyllis heterocirrata (Family Syllidae), Euchone sp. (Family Sabellidae) and Litocorsa acuminata (Family Pilargidae). L. acuminata was once a prevalent species in the infaunal communities at impacted sites, but its abundance decreased over the course of the study. None were found in impacted site samples after June 2003. P. heterocirrata and Euchone sp. were consistently found at Sites E and FW, respectively.

Species that most characterized impacted infaunal communities include Ophryotrocha adherens (Family Dorvilleidae), Capitella capitata (Family Capitellidae) species complex and Myriochele oculata (Family Oweniidae). C. capitata has been consistently present at impacted sites since the beginning of this study. Of the 1875 O. adherens counted in this study, $78.8 \%$ were found in Site U samples and $95.1 \%$ were found in samplings after December 2002. While SIMPER may indicate $M$. oculata as one of the most characteristic polychaetes of impacted samples, data also show it as a member of the ambient infaunal community. It was consistently present at control sites and had elevated abundances at both impacted sites until December 2002, after which it had nearly disappeared from Site U.

Table 2. Results of 2-way crossed ANOSIM where tests (999 permutations per test) for site groups were averaged over sampling groups and vice versa. ${ }^{*}$ Significance level at $\alpha=0.05$

\begin{tabular}{|ll|}
\hline & Rho \\
\hline November 2001-November 2004 & \\
$\quad$ Site & $0.542^{*}$ \\
Sampling & $0.317^{*}$ \\
November 2001-February 2003 & \\
$\quad$ Site & $0.436^{*}$ \\
$\quad$ Sampling & 0.047 \\
June 2003-November 2004 & $0.726^{*}$ \\
Site & 0.044 \\
\hline
\end{tabular}




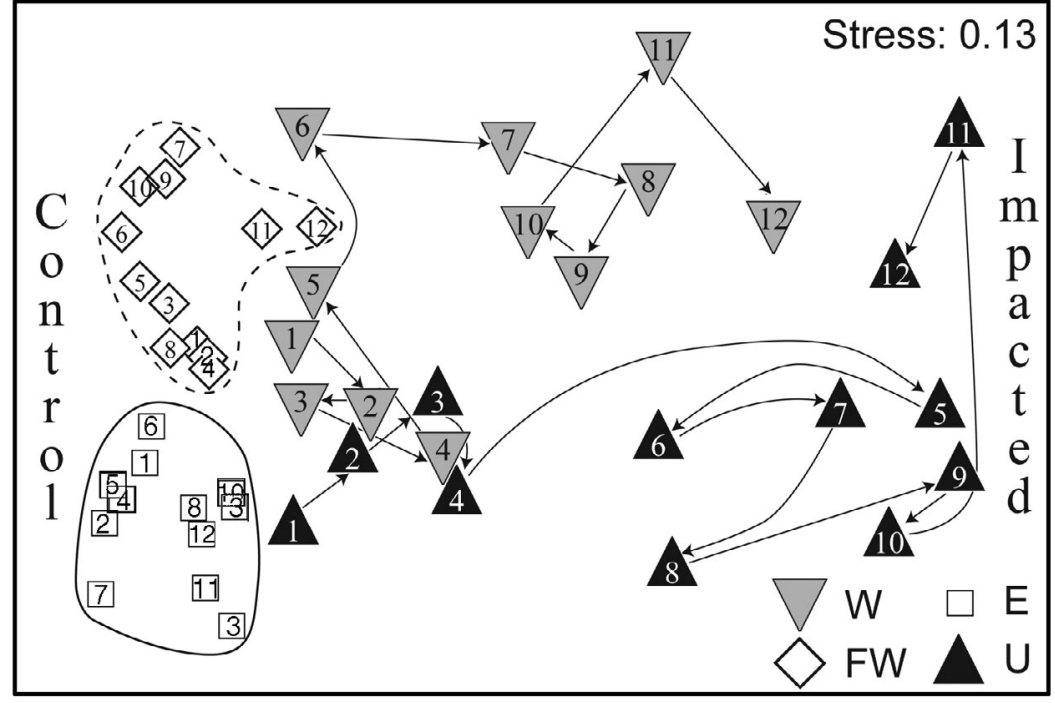

Fig. 8. A non-metric multi-dimensional scaling illustrates a (dis)similarity matrix on a 2-dimensional plot. Distances between points on map indicate relative similarity between infaunal communities of those 2 points. Control samples showed little variation between samplings. This plot illustrates development of Site $\mathrm{U}$ from an enriched site (Nov 01-Jan 02) with high species richness and abundance to a grossly impacted site dominated by a few opportunistic species (Dec 02-May 04). Site W from June 2003 has also diverged from W group toward grossly impacted U group
The 5 species with the highest contribution to the Bray-Curtis dissimilarity and lowest standard deviation of that coefficient are listed in Table 4. Armandia intermedia (Family Ophelidae) was found in elevated abundances in impacted samples but fewer numbers in control samples (Table 4) and may be a discriminating species between the 2 sample groups. Species that were found to characterize control or impacted sites had generally high discriminatory potential as well. Capitella capitata, Ophryotrocha adherens, Pionosyllis heterocirrata and Euchone sp. were the top 4 discriminatory species between control and impacted sites. The 2 opportunistic species $C$. capitata and $O$. adherens were more abundant at impacted sites, while $P$. heterocirrata and Euchone sp. were more abundant at control sites.

Table 3. Results of SIMPER analyses identifying species that contribute most to the similarity of compared replicates within a site as well as the similarity between group samples. ${ }^{\mathrm{A}, \mathrm{B}, \mathrm{C}}$ indicate rank of each characteristic species based on similarity for each site

\begin{tabular}{|c|c|c|c|c|c|c|c|c|c|}
\hline Species & $\begin{array}{c}\text { Avg. } \\
\text { abundance }\end{array}$ & $\begin{array}{l}\text { Avg. } \\
\text { similarity }\end{array}$ & $\begin{array}{l}\text { Contrib. } \\
(\%)\end{array}$ & Ratio & Species & $\begin{array}{c}\text { Avg. } \\
\text { abundance }\end{array}$ & $\begin{array}{c}\text { Avg. } \\
\text { similarity }\end{array}$ & $\begin{array}{c}\text { Contrib. } \\
(\%)\end{array}$ & Ratio \\
\hline \multicolumn{5}{|c|}{ Group E } & \multicolumn{5}{|c|}{ Group U } \\
\hline Avg. similarity $=57.64$ & & & & & Avg. similarity $=27.18$ & & & & \\
\hline Pionosyllis heterocirrata $^{\mathrm{A}}$ & 73.33 & 13.58 & 23.57 & 6.20 & Capitella capitata ${ }^{\mathrm{A}}$ & 93.75 & 10.49 & 38.59 & 11.40 \\
\hline Litocorsa acuminata $^{\mathrm{C}}$ & 35.25 & 9.15 & 15.88 & 3.30 & Ophryotrocha adherens ${ }^{\mathrm{B}}$ & 137.92 & 5.86 & 21.55 & 10.85 \\
\hline Myriochele oculata $^{\mathrm{B}}$ & 29.67 & 7.33 & 12.71 & 3.44 & Hesionidae sp. & 15.00 & 2.19 & 8.07 & 1.38 \\
\hline Prionospio cirrifera & 22.75 & 5.34 & 9.26 & 2.63 & Neanthes arenaceodentata & 13.17 & 1.69 & 6.22 & 2.11 \\
\hline \multirow{3}{*}{ Heteropodarke sp. } & 18.33 & 4.90 & 8.50 & 1.63 & Capitellidae sp. & 24.17 & 1.56 & 5.73 & 1.61 \\
\hline & & & & & Myriochele oculata ${ }^{\mathrm{C}}$ & 30.75 & 1.11 & 4.07 & 3.58 \\
\hline & \multicolumn{4}{|l|}{ Group FW } & \multicolumn{5}{|c|}{ Group W } \\
\hline Avg. similarity $=51.04$ & & & & & Avg. similarity $=25.78$ & & & & \\
\hline Litocorsa acuminata $^{\mathrm{B}}$ & 30.58 & 11.48 & 22.49 & 7.04 & Capitella capitata $^{\mathrm{B}}$ & 103.50 & 5.91 & 22.91 & 5.28 \\
\hline Euchone sp. ${ }^{\mathrm{A}}$ & 36.58 & 9.48 & 18.57 & 8.70 & Myriochele oculata $^{\mathrm{A}}$ & 30.00 & 4.55 & 17.65 & 5.91 \\
\hline Myriochele oculata $^{\mathrm{C}}$ & 17.42 & 5.97 & 11.70 & 4.23 & Prionospio steenstrupi & 10.50 & 2.65 & 10.30 & 3.01 \\
\hline Prionospio cirrobranchiata & 15.58 & 5.44 & 10.65 & 3.78 & Armandia intermedia & 23.17 & 2.56 & 9.93 & 4.34 \\
\hline \multirow[t]{2}{*}{ Prionospio steenstrupi } & 14.75 & 5.09 & 9.97 & 3.01 & Litocorsa acuminata & 17.92 & 1.38 & 5.36 & 2.76 \\
\hline & & & & & Ophryotrocha adherens ${ }^{\mathrm{C}}$ & 33.00 & 0.79 & 3.05 & 4.94 \\
\hline \multicolumn{5}{|c|}{ Group Control } & \multicolumn{5}{|c|}{ Group Impact } \\
\hline Avg. similarity $=44.88$ & & & & & Avg. similarity $=24.80$ & & & & \\
\hline Litocorsa acuminata $^{\mathrm{C}}$ & 32.92 & 10.23 & 22.80 & 5.47 & Capitella capitata ${ }^{\mathrm{B}}$ & 98.63 & 7.50 & 30.26 & 8.06 \\
\hline Myriochele oculata & 23.54 & 6.47 & 14.41 & 3.92 & Ophryotrocha adherens ${ }^{\mathrm{A}}$ & 85.46 & 3.21 & 12.94 & 9.44 \\
\hline Euchone sp. ${ }^{\mathrm{B}}$ & 22.54 & 4.06 & 9.05 & 5.80 & Myriochele oculata ${ }^{\mathrm{C}}$ & 30.38 & 2.55 & 10.29 & 5.20 \\
\hline Pionosyllis heterocirrata $^{\mathrm{A}}$ & 37.63 & 3.82 & 8.51 & 6.26 & Armandia intermedia & 21.00 & 1.79 & 7.23 & 3.65 \\
\hline Prionospio cirrobranchiata & 13.29 & 3.44 & 7.67 & 3.34 & Hesionidae sp. & 11.54 & 1.59 & 6.42 & 1.39 \\
\hline
\end{tabular}


Table 4. Results of SIMPER analyses identifying species that contribute most to dissimilarity of compared samples within a group as well as dissimilarity between group samples. ${ }^{\mathrm{A}, \mathrm{B}, \mathrm{C}}$ indicate rank of each discriminating species based on dissimilarity for each site

\begin{tabular}{|c|c|c|c|c|c|c|c|c|c|c|c|}
\hline \multirow{3}{*}{$\begin{array}{l}\text { Species } \\
\text { Groups } \\
\text { Avg. dissimilarity }=63.78\end{array}$} & \multicolumn{2}{|c|}{ Avg. abundance } & \multirow[t]{2}{*}{$\begin{array}{l}\text { Avg. } \\
\text { dissim. }\end{array}$} & \multirow[t]{2}{*}{$\begin{array}{c}\text { Contrib. } \\
(\%)\end{array}$} & \multirow[t]{2}{*}{ Ratio } & \multirow{2}{*}{$\begin{array}{l}\text { Species } \\
\text { Groups }\end{array}$} & \multicolumn{2}{|c|}{ Avg. abundance } & \multirow[t]{2}{*}{$\begin{array}{l}\text { Avg. } \\
\text { dissim. }\end{array}$} & \multirow[t]{2}{*}{$\begin{array}{c}\text { Contrib. } \\
(\%)\end{array}$} & \multirow[t]{3}{*}{ Ratio } \\
\hline & $\mathbf{E}$ & FW & & & & & $\mathbf{U}$ & $\mathbf{W}$ & & & \\
\hline & & & & & & Avg. dissimilarity $=76.74$ & & & & & \\
\hline Pionosyllis heterocirrata & $73.33^{\mathrm{A}}$ & 1.92 & 13.63 & 21.38 & 7.57 & Ophryotrocha adherens & $137.92^{\mathrm{A}}$ & 33.00 & 17.85 & 23.26 & 19.19 \\
\hline Euchone sp. & 8.50 & $36.58^{\mathrm{B}}$ & 6.37 & 9.98 & 5.95 & Capitella capitata & 93.75 & $103.50^{\mathrm{B}}$ & 16.88 & 22.00 & 15.78 \\
\hline Litocorsa acuminata & 35.25 & $30.58^{\mathrm{C}}$ & 3.87 & 6.07 & 2.91 & Myriochele oculata & $30.75^{\mathrm{C}}$ & 30.00 & 7.31 & 9.52 & 8.12 \\
\hline Myriochele oculata & 29.67 & 17.42 & 3.62 & 5.67 & 2.62 & Armandia intermedia & 18.83 & 23.17 & 5.33 & 6.95 & 7.51 \\
\hline Prionospio cirrifera & 22.75 & 6.58 & 3.46 & 5.43 & 2.10 & Litocorsa acuminata & 9.75 & 17.92 & 3.18 & 4.14 & 3.83 \\
\hline Groups & E & $\mathbf{W}$ & & & & Groups & $\mathbf{U}$ & FW & & & \\
\hline Avg. dissimilarity $=78.46$ & & & & & & Avg. dissimilarity $=88.07$ & & & & & \\
\hline Pionosyllis heterocirrata & $73.33^{\mathrm{C}}$ & 4.42 & 12.38 & 15.79 & 8.14 & Ophryotrocha adherens & $137.92^{\mathrm{A}}$ & 0.17 & 16.81 & 19.09 & 19.32 \\
\hline Capitella capitata & 2.08 & $103.50^{\mathrm{A}}$ & 9.35 & 11.92 & 16.40 & Capitella capitata & $93.75^{\mathrm{B}}$ & 3.08 & 14.97 & 16.99 & 12.37 \\
\hline Litocorsa acuminata & 35.25 & 17.92 & 5.63 & 7.18 & 3.99 & Euchone sp. & 0.33 & $36.58^{\mathrm{C}}$ & 7.55 & 8.57 & 7.78 \\
\hline Myriochele oculata & 29.67 & 30.00 & 5.57 & 7.10 & 4.76 & Litocorsa acuminata & 9.75 & 30.58 & 6.37 & 7.24 & 5.35 \\
\hline Ophryotrocha adherens & 0.00 & $33.00^{\mathrm{B}}$ & 5.44 & 6.94 & 12.65 & Myriochele oculata & 30.75 & 17.42 & 6.35 & 7.21 & 4.96 \\
\hline Armandia intermedia & 8.58 & 23.17 & 3.99 & 5.08 & 5.96 & Neanthes arenaceodentata & a 13.17 & 0.08 & 3.29 & 3.73 & 5.77 \\
\hline Groups & $\mathbf{E}$ & $\mathbf{U}$ & & & & Groups & $\mathbf{W}$ & FW & & & \\
\hline Avg. dissimilarity $=85.65$ & & & & & & Avg. dissimilarity $=73.40$ & & & & & \\
\hline Ophryotrocha adherens & 0.00 & $137.92^{\mathrm{A}}$ & 14.09 & 16.45 & 16.98 & Capitella capitata & $103.50^{\mathrm{A}}$ & 3.08 & 10.93 & 14.90 & 17.92 \\
\hline Capitella capitata & 2.08 & $93.75^{\mathrm{B}}$ & 12.26 & 14.32 & 10.13 & Euchone sp. & 8.75 & 36.58 & 8.48 & 11.55 & 8.15 \\
\hline Pionosyllis heterocirrata & $73.33^{\mathrm{C}}$ & 12.67 & 9.72 & 11.35 & 7.97 & Litocorsa acuminata & 17.92 & 30.58 & 6.88 & 9.38 & 4.99 \\
\hline Myriochele oculata & 29.67 & 30.75 & 6.06 & 7.08 & 3.86 & Ophryotrocha adherens & $33.00^{\mathrm{B}}$ & 0.17 & 6.84 & 9.32 & 15.55 \\
\hline Litocorsa acuminata & 35.25 & 9.75 & 5.46 & 6.37 & 3.93 & Myriochele oculata & 30.00 & 17.42 & 6.63 & 9.04 & 7.37 \\
\hline & & & & & & Armandia intermedia & $23.17^{\mathrm{C}}$ & 2.75 & 5.41 & 7.37 & 8.45 \\
\hline Groups & \multirow{2}{*}{\multicolumn{5}{|c|}{ Control Impacted }} & & & & & & \\
\hline Avg. dissimilarity $=81.39$ & & & & & & & & & & & \\
\hline Capitella capitata & 2.58 & $98.63^{\mathrm{B}}$ & 11.88 & 14.59 & 14.67 & & & & & & \\
\hline Ophryotrocha adherens & 0.08 & $85.46^{\mathrm{A}}$ & 10.80 & 13.27 & 16.88 & & & & & & \\
\hline Pionosyllis heterocirrata & $37.63^{\mathrm{C}}$ & 8.54 & 6.19 & 7.61 & 7.64 & & & & & & \\
\hline Myriochele oculata & 23.54 & 30.38 & 6.15 & 7.56 & 5.39 & & & & & & \\
\hline Litocorsa acuminata & 32.92 & 13.83 & 6.09 & 7.48 & 4.65 & & & & & & \\
\hline Euchone sp. & 22.54 & 4.54 & 4.85 & 5.96 & 6.55 & & & & & & \\
\hline Armandia intermedia & 5.67 & 21.00 & 3.70 & 4.55 & 6.07 & & & & & & \\
\hline
\end{tabular}

\section{DISCUSSION}

Granulometric profiles have shown slight variation over the course of the study, but the general trends are apparent (Fig. 3). Sediment compositions between the 4 study sites are highly similar and would not likely affect infaunal community structure. Lowered ORP values resulting from microbial degradation of accumulated organic detritus may be indicative of geochemical factors affecting infaunal composition. Changes in sediment color as well as ORP may be an indication of detrimental effects of nutrient influx from the fish enclosure. Organic matter loading creates anoxic conditions due to excessive microbial oxygen consumption. Microbial sulfate reduction leads to accumulated sulfides in sediments and creates a chemical oxygen demand (Hargrave 1994). We observed a general trend of increasing difference between the average ORP values of control and impacted sites over time, indicating a shift toward anaerobic conditions due to carbon influx from the fish cages. Anaerobic conditions may influence ecological dynamics of the benthic system. Organisms with varying defenses against sulfide toxicity can tolerate microbial sulfide metabolites or leave the affected area. Consequently, the sulfide concentration in the sediment will shape the infaunal community structure by displacing nontolerant species (Vismann 1991).

The change in the infaunal community found under the fish enclosure over time follows the model progression for organic enrichment (Pearson \& Rosenberg 1978). Due to organic enrichment from the fish enclosure, impacted sites had diversity values that were initially higher than control sites. Diversity decreased (Fig. 5) as the buildup of organic material continued (Fig. 1), following a pattern illustrated by Pearson \& Rosenberg (1978). Infaunal communities under the cages were severely depressed in December 2002 when average Shannon-Weiner diversity values were among the lowest of the study and one Site U replicate 
was nearly devoid of infauna. The Site U sediments from November 2001 had an enriched benthic environment with high Shannon-Weiner diversity values. At 13 mo after the initial sampling (November 2001), Site U from sampling 5 (December 2002) had evolved into a grossly polluted site with a severely depressed polychaete community (Fig. 5). The polychaete community found underneath the enclosure at Site U was the first to respond to changing environmental conditions. The polychaete community found $80 \mathrm{~m}$ down-current at site $\mathrm{W}$ followed, indicating that the footprint of effect had spread from beyond the immediate vicinity of the enclosure to nearby environments. By the November 2004 sampling, Sites U and W had become highly similar in polychaete community structure.

The nMDS ordination illustrates relatively little species turnover occurring in control sites compared to high species turnover in impacted sites. The relative lack of species turnover at control sites indicates that there may not be a noticeable seasonal trend in species composition or a natural cycle of succession in the area, a stark contrast to the communities found at impacted sites. Polychaete communities at impacted sites that were initially relatively similar to control site communities shifted in response to decreasing redox potential, possibly due to decreasing oxygen concentrations. This is evident in both univariate and multivariate statistical analyses. Regression analyses of univariate Shannon-Weiner diversity values indicate that diversity has decreased over time but increases with distance away from the effluent source. ANOSIM results also indicate significant differences in polychaete community structure over both space and time. However, when we break down the analysis by using subsets of data involving only the first 6 samplings, trends found in time are non-significant. This result is repeated by an analysis involving only the last 6 samplings. Concurrently, significant differences can be found between impacted and control sites in all analyses indicating significant effect of mariculture enrichment on polychaete community structure. This suggests that species turnover may occur over time in the absence of enrichment, but such a process is more gradual and only evident if we perform low-resolution analyses.

While species composition changed with each sampling, a few opportunistic polychaete species have consistently held the top rank of species abundance at impacted sites. The nearly exclusive presence of opportunistic polychaetes Capitella capitata and Ophryotrocha adherens at impacted sites suggests that they are indicative of perturbed environments. Likewise, the nearly exclusive presence of Pionosyllis heterocirrata and Euchone sp. at control sites suggests that their presence may be indicative of ambient environ- mental conditions unaffected by organic enrichment. This pattern of distribution was also found in previous benthic studies along the southern shores of $\mathrm{O}^{\prime}$ ahu (Bailey-Brock 1996, Paavo et al. 2000, Bailey-Brock et al. 2001, Swartz et al. 2001, Bybee \& Bailey-Brock 2003).

Benthic studies in the Mámala Bay region have shown that Pionosyllis heterocirrata is a widespread species whose presence is expected in the ambient infaunal community. Euchone sp. has been found to have an antithetical distribution to Ophryotrocha adherens in the benthos of nearby sewage outfall areas (Bailey-Brock et al. 2002, Swartz et al. 2003a,b, 2004). Having achieved high abundances during early stages of organic enrichment, a polychaete such as Myriochele oculata may be an early indicator of organic enrichment (Davis 1987). Its gradual disappearance with increasing intensity and duration of enrichment suggests a low tolerance of eutrophication effects. $C$. capitata populations respond to intermediate levels of organic enrichment and reach peak abundances before conditions in the environment are strongly enriched. The succession of indicators terminates with $O$. adherens that reach peak abundances when organic levels are high, anoxic conditions may be present and other species have declined. The presence of $O$. adherens and Capitellids has changed the trophic composition of the infaunal communities at impacted sites. Other studies have shown that both C. capitata and various Ophryotrocha spp. are opportunistic species tolerant of organic carbon loading (Bailey-Brock et. al. 2002, Brooks et al. 2003, Bybee \& Bailey-Brock 2003, Davis 1987, Henderson \& Ross 1995). We believe that $M$. oculata, C. capitata and $O$. adherens represent a succession of attrition to anoxia. Members of the ambient community show varying levels of tolerance to organic enrichment. Species that disappear under enriched nutrient regimes are less tolerant to attrition from anoxia. Indicator species such as $M$. oculata, $C$. capitata and $O$. adherens are increasingly more tolerant to attrition resulting from enrichment anoxia and increasingly better competitors under hypernutrification.

Infaunal communities found at control sites have been characterized by species commonly found in ambient infaunal communities unaffected by enrichment processes. Species such as Pionosyllis heterocirrata are ubiquitously found throughout the southern shore of O'ahu (Bailey-Brock 1996, Bailey-Brock et al. 2002, Swartz et al. 2004), which leads us to believe that it is a regional indicator of benthic health. Litocorsa acuminata and Euchone sp. are not as ubiquitously found throughout Mámala Bay but were commonly found species in nearby sewage outfall benthic studies (Swartz et al. 2003a,b). These results reflect the find- 
ings of similar benthic studies conducted within Mámala Bay (Bailey-Brock et al. 2002). The relative consistency of the infaunal community structure found at control sites in this and other nearby benthic studies serves as a benchmark for benthic health in the region.

The conclusions based on these data indicate that the gradual buildup of organic detritus under the cage has drastically changed the infaunal community structure by displacing indicators of healthy benthic environments such as Pionosyllis heterocirrata with indicators of organic enrichment, such as Capitella capitata and Ophryotrocha adherens. Evolution of the benthic environment is illustrated by the nMDS as well as average Shannon-Weiner diversity values. The progression of Site $U$ from a slightly enriched site in November 2001 to a grossly affected site by December 2002 is illustrated in reference to a generalized Pearson-Rosenberg model (Fig. 9). The nMDS illustrates the evolution of Site W from a normal to slightly enriched site in November 2001 to a heavily impacted site by June 2003. The comparisons display examples of both temporal and spatial applications of the Pearson-Rosenberg model. Site U, which is directly under the mariculture enclosures, reflects results of the most intense nutrient enrichment effects. At $40 \mathrm{~m}$ downcurrent Site $\mathrm{W}$ is influenced by a diluted nutrient enrichment regime. While the benthos at Site U had reached grossly affected conditions within 13 mo of sampling, the benthos at Site W only reached indicated heavily impacted conditions in 23 mo. ShannonWeiner diversity values at Site $\mathrm{W}$ and nMDS results show that sustained changes in community structure at

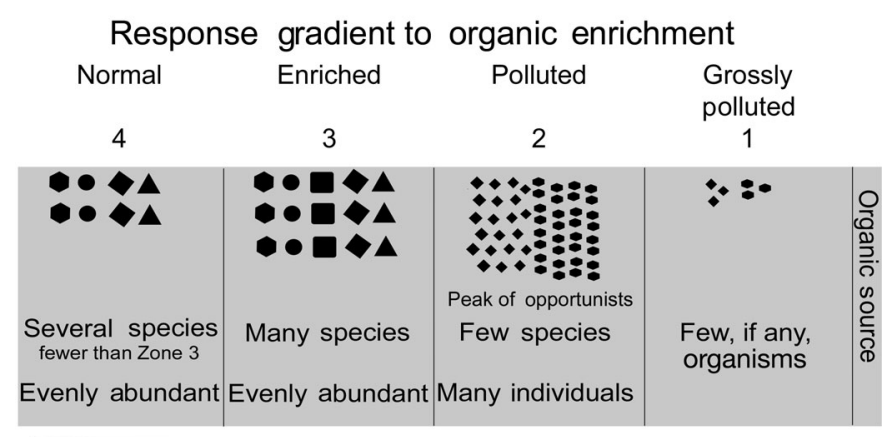

Oxygen level

\section{Toxics}

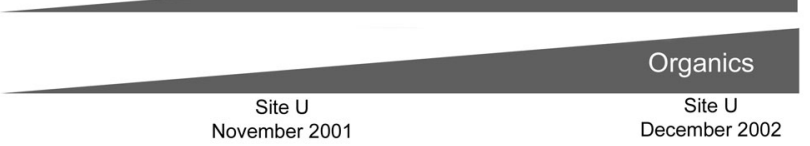

Fig. 9. Pearson-Rosenberg's model predicts a response gradient to organic enrichment. Species richness is highest in Zone 3 where an optimal balance between organic levels and oxygen levels facilitates infaunal community growth. This model is applicable to both temporal and geographical scales
Site W were evident beginning with the October 2003 sampling. Results of earlier studies showed similar responses of Capitellids and $O$. adherens to fish food and wastes (Bybee \& Bailey-Brock 2002). Population abundances returned to preculture levels in less than 2 mo after feeding ended. It is not known if the infauna would return to preculture levels in the present case because both the stocking density and duration under culture conditions have increased, resulting in larger amounts of feed added and affected bottom. Although the footprint of eutrophication effects increased westward during this study, influences were localized to areas immediately surrounding the fish enclosure as neither the MDS nor Shannon-Weiner diversity levels at Site FW (390 m down-current) indicated notable changes in infaunal community structure. This may be attributed to one of the advantages of open-water mariculture over those established in embayments: more rapid dilution and dispersal of the nutrient wastes due to greater volume of water flow through the enclosure site. Despite the open-water location and alongshore currents, the effects of fish feed and waste on the benthic polychaete community were evident.

Acknowledgements. We are grateful to Dr. C. Helsley for financial support, City and County of Honolulu Oceanographic team for field support, Cates International and Safety Boats of Hawai'i for site access and feed data. Invertebrate identifications were conducted at the University of Hawai'i Wormlab. A. Fukunaga advised on data analysis. Dr. R. Swartz and P. R. Aldrich reviewed earlier drafts of the manuscript. We are grateful to A.C. Lui for her support. We thank Dr. A. Blanchard (University of Alaska) for his constructive comments that were integral to the writing of this paper and Dr. A. Taylor (University of Hawai'i) for his invaluable assistance with the statistical analysis of the data and final review of the paper. We are grateful for the constructive comments from 3 anonymous reviewers. This research fulfilled part of the MS degree requirements for $\mathrm{H}$. W. Lee and was funded in part by Grant \# NA16RG-1634 from NOAA to Dr. C. Helsley (University of Hawai'i) of the Hawai'i Offshore Aquaculture Research Program Phase III.

\section{LITERATURE CITED}

Bailey-Brock JH (1987) Phylum Annelida. In: Devaney DM, Eldridge LG (eds) Reef and shore fauna of Hawaii. Honolulu, Hawaii, Bishop Museum Press, Bishop Museum Special Publication 64.3:213-454

Bailey-Brock JH (1996) Definition of indicator species for pollution monitoring in Mamala Bay, O’ahu, Hawaii. Mamala Bay Study Commission MB-9 Vol 2

Bailey-Brock JH, Paavo B, Barret BM, Dreyer J (2001) Changes in pollution indicators at the Sand Island sewage outfall MTS/IEEE, Oceans 2001, p 1401-1407

Bailey-Brock JH, Paavo B, Barret BM, Dreyer J (2002) Polychaetes associated with a tropical ocean outfall: synthesis of a biomonitoring program off O'ahu, Hawai'i. Pacif Sci 56:459-479

Brooks KM, Stierns AR, Mahnken CVW, Blackburn DB (2003) 
Chemical and biological remediation of the benthos near the Atlantic salmon farms. Aquaculture 219:355-377

Bustos-Baez S, Frid C (2003) Using indicator species to assess the state of macrobenthic communities. Hydrobiologia 496:299-309

Bybee DR, Bailey-Brock JH (2003) Effect of a Hawaiian open ocean fish culture system on the benthic community. In: Bridger CA, Costa-Pierce BA (eds) Open ocean aquaculture: from research to commercial reality. World Aquaculture Society, Baton Rouge, LA, p 119-128

Carroll ML, Cochrane S, Fieler R, Velvin R, White P (2003) Organic enrichment of sediments from salmon farming in Norway: environmental factors, management practices, and monitoring techniques. Aquaculture 226:165-180

Chambers M, Zimmerman J, Apeitos A (2001) Growout techniques for the Pacific threadfin Polydactylus sexfilis. Center for Tropical and Subtropical Aquaculture, Publ No. 145. Oceanic Institute, Waimanalo, HI

Clarke KR, Warwick RM (2001) Change in marine communities: an approach to statistical analysis and interpretation. PRIMER-E, Plymouth

Crawford C (2003) Environmental management of marine aquaculture in Tasmania, Australia. Aquaculture 226: 129-138

Davis DA (1987) Analysis of sublittoral benthic habitats in the vicinity of the Sand Island deep ocean sewage outfall: community structure and indicator organisms [thesis]. Department of Zoology, University of Hawaii, Honolulu, HI

Fernandes TF, Eleftheriou A, Ackefors $\mathrm{H}$, Eleftheriou $\mathrm{M}$ and 7 others (2001) The scientific principles underlying the monitoring of the environmental impacts of aquaculture. J Appl Ichthyol 17:181-193

Gamenick I, Abbiati M, Giere O (1998) Field distribution and sulphide tolerance of Capitella capitata (Annelida: Polychaeta) around shallow water hydrothermal vents off Milos (Aegean Sea). A new sibling species? Mar Biol 130: 447-453

Grassle JF, Grassle JP (1974) Opportunistic life histories and genetic systems in marine benthic polychaetes. J Mar Res 32:253-284

Gray JS, Clarke KR, Warwick RM, Hobbs G (1990) Detection of initial effects of pollution on marine benthos: an example from the Ekofisk and Eldfisk oilfields, North Sea. Mar Ecol Prog Ser 66:285-299

Hargrave BT (1994) Modelling benthic impacts of organic enrichment from marine aquaculture. Canada Technical Report on Fisheries and Aquatic Science, Report No. 1949, Bedford Institute of Oceanography, Dartmouth, Nova Scotia

Hedges JI, Stern JH (1984) Carbon and nitrogen determinations of carbonate-containing solids. Limnol Oceanogr 29: $657-663$

Henderson AR, Ross DJ (1995) Use of macrobenthic infaunal communities in the monitoring and control of the impact of marine cage fish farming. Aquacult Res 26:659-678

Henderson A, Gamito S, Karakassis I, Pederson P, Smaal A (2001) Use of hydrodynamic and benthic models for managing environmental impacts of marine aquaculture. J Appl Ichthyol 17:163-172

Krassulya N (2001) Choice of methodology for marine pollution monitoring in intertidal soft-sediment communities. CBM:s Skriftserie 3:131-148

McCarthy S (1996) Patterns of spatial and temporal variability in Hawaiian soft bottom benthos. PhD dissertation, Uni-

Editorial responsibility: Charles Birkeland (Contributing Editor), Honolulu, Hawaii, USA versity of Hawaii, Manoa, Honolulu, HI

Minitab (2000) www.minitab.com

Paavo B, Bailey-Brock JH, Akesson B (2000) Morphology and life history of Ophryotrocha adherens sp. nov. (Polychaeta, Dorvilleidae). Sarsia 85:251-264

Pearson TH, Rosenberg R (1978) Macrobenthic succession in relation to organic enrichment and pollution of the marine environment. Oceanogr Mar Biol Annu Rev 16:229-311

Pocklington P, Scott DB, Schafer CT (1994) Polychaete response to different aquaculture activities. In: Actes de la 4ème Conference Internationale des Polychetes 162: 511-520

Pohle G, Frost B, Findlay R (2001) Assessment of regional benthic impact of salmon mariculture within the Letang Inlet, Bay of Fundy. ICES J Mar Sci 58:417-426

PRIMER-E (2002) Plymouth routines in multivariate ecological research. PRIMER 5 for Windows version 5.2.9. PRIMER-E, Plymouth

Ritz DA, Lewis ME, Shen M (1989) Response to organic enrichment of infaunal macrobenthic communities under salmonid seacages. Mar Biol 103:211-214

Roberts PJW (1995) Near-field modeling of the Mamala Bay outfalls. Water Sci Technol 32:159-166

Sanders HL (1958) Benthic studies in Buzzards Bay. I. Animalsediment relationships. Limnol Oceanogr 3(3):245-258

Simonini R (2002) Distribution and ecology of the genus Ophryotrocha (Polychaeta: Dorvilleidae) in Italian harbors and lagoons. Vie Milieu 51:59-65

Swartz RC, Bailey-Brock JH, Cooke WJ, Kay EA (2001) Macrobenthos monitoring near the Sand Island and Barbers Point ocean outfalls, O'ahu, Hawai'i. MTS/IEEE, Oceans 2001, p 1408-1416

Swartz RC, Bailey-Brock JH, Cooke WJ, Kay EA (2003a) Benthic faunal sampling adjacent to Sand Island Ocean Outfall, O'ahu, Hawai'i, August 2002. Water Resources Research Center, University of Hawai'i at Manoa, Honolulu, HI

Swartz RC, Bailey-Brock JH, Cooke WJ, Kay EA (2003b) Benthic faunal sampling adjacent to the Barbers Point Ocean Outfall, O'ahu, Hawai'i, January 2003. Report No. PR2003-08, Water Resources Research Center, University of Hawai'i at Manoa, Honolulu, HI

Swartz RC, Bailey-Brock JH, Cooke WJ, Kay EA (2004) Regional monitoring of benthic fauna in Mamala Bay, O'ahu, Hawai'i, August 2003. Report No. PR-2004-06, Water Resources Research Center, University of Hawai'i at Manoa, Honolulu, HI

Titcomb M (1972) Native use of fish in Hawaii. University of Hawaii Press, Honolulu, HI

Tsutsumi H (1987) Population dynamics of Capitella capitata (Polychaeta; Capitellidae) in an organically polluted cove. Mar Ecol Prog Ser 36:139-149

Tsutsumi H (1990) Population persistence of Capitella sp. (Polychaeta; Capitellidae) on a mud flat subject to environmental disturbance by organic enrichment. Mar Ecol Prog Ser 63:147-156

Tsutsumi H (1995) Impact of fish net pen culture on the benthic environment of a cove in south Japan. Estuaries 18: 108-115

Vismann B (1991) Sulfide tolerance: physiological mechanisms and ecological implications. Ophelia 34:1-27

Yokoyama H (2002) Impact of fish and pearl farming on the benthic environments in Gokasho Bay: evaluation from seasonal fluctuations of the macrobenthos. Fish Sci 68: $258-268$

Submitted: June 7, 2005; Accepted: August 5, 2005

Proofs received from author(s): December 21, 2005 